\title{
Proposta metodológica para identificação de riscos associados ao relevo e antropização em áreas marginais aos recursos hídricos
}

\author{
Methodological proposal for identification of risks associated with relief and antropization in \\ marginal areas of water resources \\ V. C. Simonetti ${ }^{1}$; D. C. C. Silva ${ }^{2 *}$ A. H. Rosa ${ }^{1}$ \\ ${ }^{1}$ Universidade Estadual Paulista (Unesp), Instituto de Ciência e Tecnologia de Sorocaba (ICTS) \\ ${ }^{2}$ Universidade Estadual Paulista, Campus Experimental de Registro \\ *darllanamb@yahoo.com.br \\ (Recebido em 29 de agosto de 2018; aceito em 25 de fevereiro de 2019)
}

\begin{abstract}
A supressão das matas ciliares prejudica a integridade dos recursos hídricos, refletindo na qualidade da água, podendo comprometer a biota e a qualidade de vida da população, tornando indispensável estudos que avaliem os potenciais riscos ambientais. Assim, este estudo objetivou a identificação dos riscos associados às áreas de preservação permanente marginais aos cursos de água da APA Itupararanga com o auxílio de geoprocessamento. Os métodos basearam-se na sobreposição de diferentes planos de informação cartográficas em ambiente de Sistema de Informação Geográfica e Sensoriamento Remoto. Os resultados revelaram que 36,07\% das áreas de preservação permanente da APA possuem classes de fragilidade ambiental associados ao relevo classificadas em média, forte e muito forte. As classes de riscos incluem além do relevo, o uso do solo no entorno das áreas de APP e revelaram que 77,37\% da APA possui cobertura vegetal. Os riscos classificados como muito baixo e baixo totalizaram 19,79\%, e os riscos médio, alto e muito alto apresentaram, respectivamente, 2,39\%, 0,42\% e 0,03\%. As classes de riscos apresentadas no estudo indicaram que as áreas de APP sugerem reflexos da elevada antropização da área, sendo necessárias constantes fiscalizações e ações que visem minimizar as atividades que causam a degradação das matas ciliares.

Palavras-chave: mata ciliar, geoprocessamento, risco ambiental
\end{abstract}

The suppression of riparian forests harms the integrity of water resources, reflecting on water quality, which can affect the health and population quality of life, making studies that assess potential environmental risks indispensable. Therefore, this study aimed to identify the risks associated with the permanent preservation in marginal areas in the Itupararanga EPA with the aid of geoprocessing. The methods were based on the overlapping of different cartographic information plans in the Geographic Information System and Remote Sensing environment. The results showed that $36.07 \%$ of the permanent preservation areas (PPA) of the EPA have classes of environmental fragility associated to the relief classified in average, strong and very strong. The results showed that $36.07 \%$ of the permanent preservation areas of the EPA have classes of environmental fragility associated to the relief classified in average, strong and very strong. The risk classes include, the relief, the land use surroundings of PPA and revealed that $77.37 \%$ of the EPA has vegetation cover. The risks classified as very low and low amounted $19.79 \%$, and the medium, high and very high risks presented, respectively, $2.39 \%, 0.42 \%$ and $0.03 \%$. The risk classes presented in the study indicated that the areas of PPA suggest reflections of the high anthropization of the area, being necessary constant inspections and actions that aim to minimize the activities that cause the degradation of the riparian forests. Keywords: riparian forest, geoprocessing, environmental risk

\section{INTRODUÇÃO}

As atividades antrópicas têm influenciado amplamente na qualidade do ambiente, causando alterações em diferentes aspectos ambientais. Assim, o avanço da degradação compromete a qualidade de vida da população e dos recursos naturais, provocando significativas alterações no uso da terra, contaminação do solo, perda de florestas e biodiversidade.

O desmatamento das florestas tem sido tão intenso no mundo todo, que muitos países industrializados não possuem mais florestas nativas. Não obstante, o Brasil possui um passado 
sombrio e pouco amistoso com suas florestas. Alguns biomas, como a Mata Atlântica e Cerrado, foram quase extinguidos em sua totalidade, restando apenas alguns fragmentos que, apesar de serem protegidos por leis, continuam sendo devastados até os dias atuais [1].

Os ciclos econômicos do Brasil, principalmente os concernentes aos municípios paulistas, foram fundamentados em processos de devastação da Mata Atlântica e do Cerrado. A ocupação das terras no território nacional ocorreu, em grande maioria, pela proximidade dos rios como forma de garantir a subsistência, e, também, pela necessidade de navegação [2]. No entanto, as ocupações de áreas de interesse ambiental ainda acontecem corriqueiramente, causando significativos impactos socioambientais [3]. Nesse contexto, a supressão das matas ciliares prejudica severamente a integridade dos recursos hídricos, uma vez que essas áreas atuam na retenção de partículas e materiais coloidais que podem aportar os corpos de água, protegendo a integridade do solo nas margens dos rios [4, 5, 6]. Assim, as áreas marginais aos cursos de água possuem uma fragilidade natural intrínseca.

O estudo realizado por Ross (1994) [7], analisou a fragilidade ambiental de ambientes naturais, salientando que o conhecimento dos aspectos da paisagem, como relevo, tipo de solo, clima, vegetação, hidrologia, entre outros elementos do estrato geográfico, é imprescindível para a caracterização da fragilidade empírica desses ambientes. O mesmo autor se refere ao homem como principal ator das interferências dos processos respectivos aos desequilíbrios ecossistêmicos. De acordo com Tricart (1977) [8], autor que realizou estudos respectivos à Unidades Ecodinâmicas, os ambientes possuem um sistema de equilíbrio, que uma vez perturbado ou mesmo interrompido, pode provocar severas alterações ambientais. Ainda, o autor abordou o conceito que se baseia no princípio da relação intrínseca entre os atributos bióticos e abióticos do ambiente.

Como subsídios na otimização dos impactos ambientais, diversas leis foram fomentadas, sendo o Brasil o detentor de um dos maiores acervos legislativo do planeta, fato que por si só não resulta em proteção ambiental efetiva. No tocante aos recursos hídricos foram instituídas políticas e legislações específicas, como a Política Nacional dos Recursos Hídricos (PNRH), por meio da lei $\mathrm{n}^{\circ}$ 9.433/1997 [9], que estabelece a bacia hidrográfica como unidade territorial de gestão, e o Novo Código Florestal pela lei $\mathrm{n}^{\mathrm{o}}$ 12.651/2012 [10], que delimita as áreas de preservação permanente (APP).

Para tanto, torna-se indispensável o uso de tecnologias que venham de encontro a essa prerrogativa e que auxiliem na fiscalização, avaliação, diagnóstico e monitoramento dos recursos naturais e, neste cenário, o uso de geotecnologias tem se destacado [11].

Neste sentido, a aplicabilidade de Sistemas de Informação Geográfica (SIG) na gestão dos recursos naturais possui uma notável relevância, uma vez que surgem novas tecnologias e melhoramentos de satélites no decorrer do tempo, enquanto as análises decorrentes de amostragens in situ somente são bastante onerosas, e nem sempre são capazes de traduzir as reais condições do ambiente [11, 12]. Por essa razão, o uso de geotecnologias é copiosamente utilizado na análise e identificação de diferentes aspectos do ambiente $[11,12,13,14,15,16,17,18,19$, 20,21].

Diante do exposto, o estudo objetivou a identificação dos riscos associados às áreas de preservação permanente marginais aos cursos de água da APA Itupararanga com o auxílio de geoprocessamento, possibilitando identificar as áreas prioritárias para recomposição da vegetação com vistas a manutenção e proteção da qualidade da água dos recursos hídricos presentes na APA Itupararanga.

\section{MATERIAL E MÉTODOS}

\subsection{Caracterização da área de estudo}

A área de estudo está inserida na Unidade de Gerenciamento de Recursos Hídricos do Sorocaba e Médio Tietê (UGRHI 10 - SMT) na categoria de Área de Proteção Ambiental (APA), denominada APA Itupararanga, compreendendo os afluentes da sub-bacia do Alto Sorocaba, sendo o rio Una juntamente com os rios Sorocabuçu e o Sorocamirim que se convergem, 
constituindo o principal reservatório de captação de água do município de Sorocaba, o reservatório de Itupararanga [22, 23].

A Bacia Hidrográfica do Alto Sorocaba coincide com os limites da APA Itupararanga, apresentando uma área de $929 \mathrm{~km}^{2}$, que abrange cerca de oito municípios, como Votorantim, Alumínio, Mairinque, Ibiúna, São Roque, Piedade, Vargem Grande Paulista e Cotia. O reservatório está localizado no alto curso do rio Sorocaba, sob concessão da Companhia Brasileira de Alumínio (CBA), estando inserido no Aquífero Cristalino [23, 24].

O clima predominante é de verão chuvoso e inverno com estiagem, apresentando uma pluviosidade média anual de $1.492 \mathrm{~mm}$, no qual janeiro representa o mês com maior precipitação, sendo $248 \mathrm{~mm}$ e agosto o mês mais seco com $43 \mathrm{~mm}$ [23].

A vegetação é composta pelos domínios de Floresta Ombrófila Densa. A economia da bacia hidrográfica é pautada na produção agrícola, sendo constituída em sua maioria por pequenas propriedades rurais [24].

Quanto aos aspectos geomorfológicos, a Bacia Hidrográfica do Alto Sorocaba está situada nos limites do Planalto Atlântico e Depressão Periférica, com classes representadas por Escarpas Festonadas, Mares de Morros, Mesas Basálticas, Morros com Serras Restritas, Morros Paralelos, Morros de Topos Achatados e Planícies Aluviais [24].

Os aspectos litológicos são constituídos por dois domínios principais, sendo o São Roque, representado por metassedimentos e metabásicas e Embu, representado pelos gnaisses. Ainda, estes Domínios apresentam diversas outras associações. Quanto aos aspectos pedológicos, são representados por três classes principais, sendo Argissolo, Cambissolo e Latossolo [24]. A Figura 1 ilustra a localização da área de estudo.

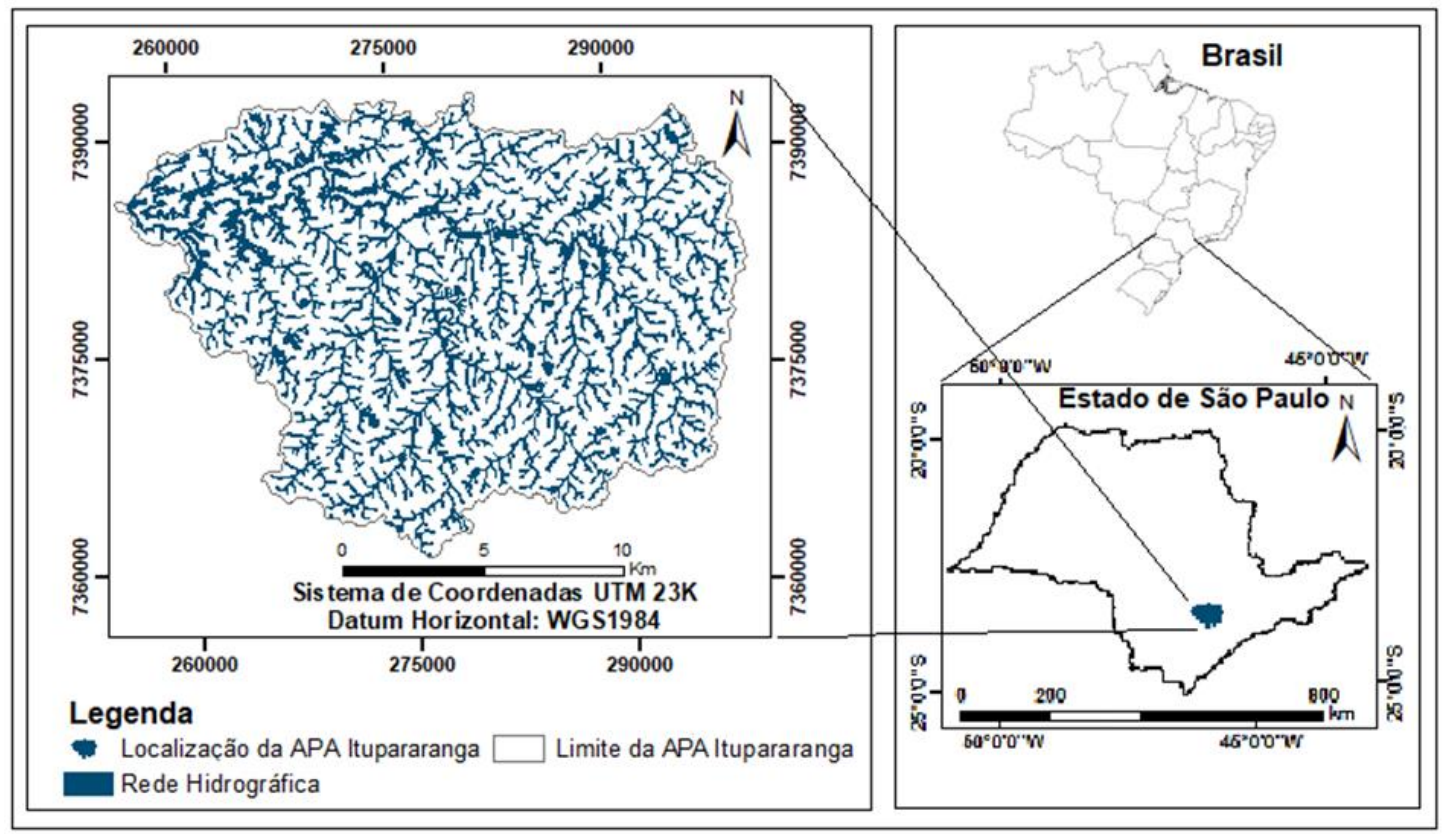

Figura 1: Localização da área de estudo na APA Itupararanga no município de Sorocaba, São Paulo.

\subsection{Análise espacial da altitude da APA Itupararanga}

A análise espacial da APA Itupararanga foi baseada na metodologia proposta por Ross (1994) [7], na qual o autor fundamenta-se no conceito preconizado por Tricart (1977) [8] de Unidade Ecodinâmica. Tal conceito se baseia no princípio da relação intrínseca entre os atributos físicos e bióticos do ambiente.

Para tanto, a investigação dos atributos físicos da APA Itupararanga consistiu na elaboração do plano de informação referente à Altitude da APA, gerado a partir do recorte da imagem denominada SF-23-Y-C proveniente do Shuttle Radar Topography Mission (SRTM), disponibilizada pela Empresa Brasileira de Pesquisas Agropecuárias (EMBRAPA) com escala de 1:250.000 no Sistema de Coordenadas Geográficas e Datum Horizontal WGS84. 


\subsection{Análise espacial da declividade da APA Itupararanga}

A partir do plano de informação da Altitude da APA Itupararanga foi gerado o plano de informação com as declividades presentes na área de estudo por meio do software ArcGis versão 10.4.1. Posteriormente foram estabelecidas cinco diferentes classes de declividade, segundo a metodologia proposta por Ross (1994) [7], sendo atribuídos diferentes pesos para cada uma das respectivas classes, conforme a Tabela 1.

Tabela 1: Classes de declividades atribuídas segundo Ross (1994).

\begin{tabular}{ccc}
\hline Valores & Categoria & Elevação \\
\hline 1 & Muito fraco & abaixo de 6\% \\
2 & Fraco & de 6 a $12 \%$ \\
3 & Médio & de 12 a $20 \%$ \\
4 & Forte & de 20 a 30\% \\
5 & Muito forte & acima de 30\% \\
\hline
\end{tabular}

Após a determinação das classes de declividade (Tabela 1), foram calculadas as respectivas áreas de cada um dos intervalos estabelecidos. Para tanto, o arquivo foi convertido de raster para um arquivo vetorial no formato de polígonos. A próxima etapa consistiu na separação das classes para identificação e cálculos das áreas de cada uma das classes presentes na área de estudo.

\subsection{Análise das classes de fragilidade ambiental das áreas de preservação permanente da APA Itupararanga a partir do relevo}

Após a obtenção do plano de informação referente à Fragilidade Ambiental da APA Itupararanga, foram calculadas as áreas de preservação permanente marginais aos cursos d'água, de acordo com as faixas preconizadas pelo Novo Código Florestal [10].

A rede hidrográfica foi adquirida junto a Coordenadoria de Planejamento Ambiental do Estado de São Paulo (CPLA) na escala de 1:250.000. Com o intuito de melhorar a acurácia dos resultados, foram analisadas separadamente as sub-bacias hidrográficas dos rios Una, Sorocabuçu, Sorocamirim e do reservatório de Itupararanga presente na APA.

\subsection{Elaboração do mapa de uso do solo da APA Itupararanga e atribuição de pesos para cada classe de uso identificada}

O plano de informação referente ao uso e ocupação do solo da APA Itupararanga foi retificado a partir dos mapas de Unidades Homogêneas de uso e ocupação do solo urbano (UHCT) e de Cobertura da Terra do Estado de São Paulo, disponibilizados pela Coordenadoria de Planejamento Ambiental do Estado de São Paulo (CPLA) na escala de 1:100.000.

Os mapas da CPLA foram gerados com imagens de alta resolução ortorretificadas do satélite SPOT (2010); imagens de RapidEye (5 m de resolução) e ortofotos de 2011 (1 m de resolução) disponibilizadas pela Empresa Paulista de Planejamento Metropolitano S/A.

A retificação do mapa foi conduzida em diferentes etapas. Inicialmente, foi realizada a reclassificação das tipologias identificadas pela CPLA em dez novas classes de usos por meio da ferramenta Reclass do módulo Spatial Analyst Tools, que permite a reclassificação de valores provenientes de arquivos raster.

A segunda etapa consistiu na retificação das áreas agrícolas da APA, sendo realizada por meio da identificação visual de imagens orbitais (ano de 2017) disponibilizadas pelo software Google Earth Pró, onde após serem identificadas, vetorizadas e extraídas, foram exportadas para o software ArcGis 10.4.1 e sobrepostas ao mapa de uso do solo pela ferramenta Overlay para retificação do mapa.

A atribuição de valores para as classes de uso do solo foi realizada de acordo com as possíveis ameaças eminentes aos corpos d'água, sendo o peso zero (0) o menor valor atribuído, uma vez que as matas exercem um papel fundamental na proteção dos recursos hídricos, e segundo a 
legislação ambiental brasileira é o estado ambiental que oferece menor impacto aos recursos hídricos. Ainda, com relação ao peso 0, este fora atribuído para diferenciação dos demais pesos no plano de informação, pois para estas áreas não há necessidade de intervenção antrópica visando a recomposição da mata ou outra medida que vise a proteção dos recursos hídricos. Nessa categoria foram incluídas todas as classes de matas (cobertura arbórea; cobertura herbácea arbustiva e área verde urbana) e os próprios corpos d'água objetos desse estudo. Embora sempre haja riscos associados, ou seja, o risco zero praticamente não exista na natureza, esse estudo retrata a importância da conservação das florestas ripárias, não sendo, portanto, atribuído nenhum peso às áreas com cobertura vegetal.

O peso 3 foi atribuído à área urbana e área desocupada, sendo designado o peso 3 devido os possíveis danos aos corpos d'água provenientes das atividades antrópicas. A contaminação dos corpos aquáticos pode ocorrer por conta do escoamento superficial resultante da precipitação atmosférica, que pode conter elementos tóxicos e contaminantes ambientais [11].

O maior valor (peso 5) foi atribuído às áreas agrícolas, loteamentos e solo exposto, que podem impactar diretamente nos corpos d'água através do arraste de sedimentos e materiais particulado [25]. Assim, as informações provenientes de cada uma das classes foram apresentadas na Tabela 2.

Tabela 2: Classes de usos do solo da APA Itupararanga, município de Sorocaba, São Paulo.

\begin{tabular}{c|c|l}
\hline Valor & Classes & \multicolumn{1}{|c}{ Caracterização } \\
\hline $\mathbf{0}$ & Cobertura arbórea & $\begin{array}{l}\text { Inclui as formações predominantemente arbóreas (floresta } \\
\text { estacional semidecídua e cerrado), incluindo as matas ciliares, } \\
\text { floresta estacional, além das florestas plantadas, como pinus e } \\
\text { eucalipto). } \\
\text { Inclui áreas cobertas por espécies forrageiras (vegetação de } \\
\text { gramíneas e leguminosas) e áreas de pasto. } \\
\text { Inclui as áreas verdes públicas, como parques e praças. }\end{array}$ \\
$\mathbf{0}$ & $\begin{array}{c}\text { Cobertura herbácea de } \\
\text { arbustiva } \\
\text { Inclui os cursos d'água, como rios, riachos e canais), além de } \\
\text { lagos e represas. } \\
\text { Inclui áreas com vegetação predominantemente aquática. } \\
\text { Inclui áreas residenciais, comerciais, industriais, áreas } \\
\text { pavimentadas (sistema viário). Também inclui áreas edificadas, } \\
\text { como chácaras residenciais e sítios distantes da zona urbana. } \\
\text { Inclui áreas destinadas às futuras ocupações urbanas, como } \\
\text { áreas com terraplanagem. } \\
\text { Inclui áreas com presença ou não de pavimentação, em estágio } \\
\text { de implantação/construção. } \\
\text { Inclui áreas com forte intervenção antrópica e áreas com } \\
\text { processos erosivos cujo solo apresenta alta vulnerabilidade. } \\
\text { Inclui todas as áreas de cultivo agrícola, incluindo as categorias } \\
\text { de culturas temporárias, semiperenes e perenes. }\end{array}$ \\
\hline $\mathbf{3}$ & Área úmida \\
\hline $\mathbf{5}$ & Área ocupada & Área desocupada \\
\hline
\end{tabular}

\subsection{Avaliação das Classes de Risco (CR) das áreas de APP marginais aos cursos de água da} APA Itupararanga

Os planos de informação gerados com as classificações das classes de fragilidade e usos do solo foram interseccionados dentro dos limites das APPs contidas na APA para identificar os distintos usos do solo, gerando como produto final, um mapa de risco das APP que serviu de subsídio para inferir sobre o estado de conservação das áreas de APP marginais aos cursos de água contidos na APA.

Para tanto, foi realizada a sobreposição de dois planos de informação, onde os novos valores foram calculados por meio de uma operação algébrica com o uso da ferramenta raster calculator, disponível no módulo Spatial Analyst Tools do software ArcGIS 10.4.1 por meio da Equação (1). 


$$
C R=\frac{C F \times U S}{25}
$$

Sendo:

US é o plano de informação referente ao mapa de uso e ocupação do solo; CF é o plano de informação referente ao mapa de classes de fragilidade e CR é o plano de informação com as Classes de Risco das APPs.

Uma vez que todos os valores variaram de 1 a 5 , com exceção do mapa de uso e ocupação do solo que apresentou um intervalo variando de 0 a 5 , o valor máximo obtido na multiplicação desses dois planos de informação é igual a 25 e o menor valor é igual a 0 , portanto, quando os valores finais são divididos por 25 , temos os valores do Indicador de Classes de Risco variando de 0 a 1.

Os valores correspondentes às Classes de Risco foram categorizados quanto ao grau de risco de carreamento de sedimentos aos corpos d'água em função dos diferentes usos do solo em suas extensões, considerando a distância preconizada pelo Novo Código Florestal [10], que determina uma faixa marginal de APP de $100 \mathrm{~m}$ para reservatórios com fins de abastecimento público e 30 $\mathrm{m}$ para rios com menos de $10 \mathrm{~m}$ de extensão. Assim, a Tabela 3 ilustra as amplitudes concernentes as cinco respectivas classes de riscos.

Tabela 3: Classificação do Indicador das Classes de Risco das matas ciliares da APA Itupararanga, município de Sorocaba, São Paulo.

\begin{tabular}{c|c}
\hline Valor & Classe \\
\hline 0,01 a 0,20 & Muito baixo \\
0,21 a 0,40 & Baixo \\
0,41 a 0,60 & Médio \\
0,61 a 0,80 & Alto \\
0,81 a 1,00 & Muito alto \\
\hline
\end{tabular}

A geração dos mapas, bem como os cálculos matriciais necessários para a obtenção das classes de riscos foram realizados no software ArcGIS versão 10.4.1.

\section{RESULTADOS E DISCUSSÃO}

A partir do uso de geoprocessamento foi analisada uma vasta área em um curto intervalo de tempo, sendo possível inferir sobre à altitude da APA Itupararanga (Figura 2). 


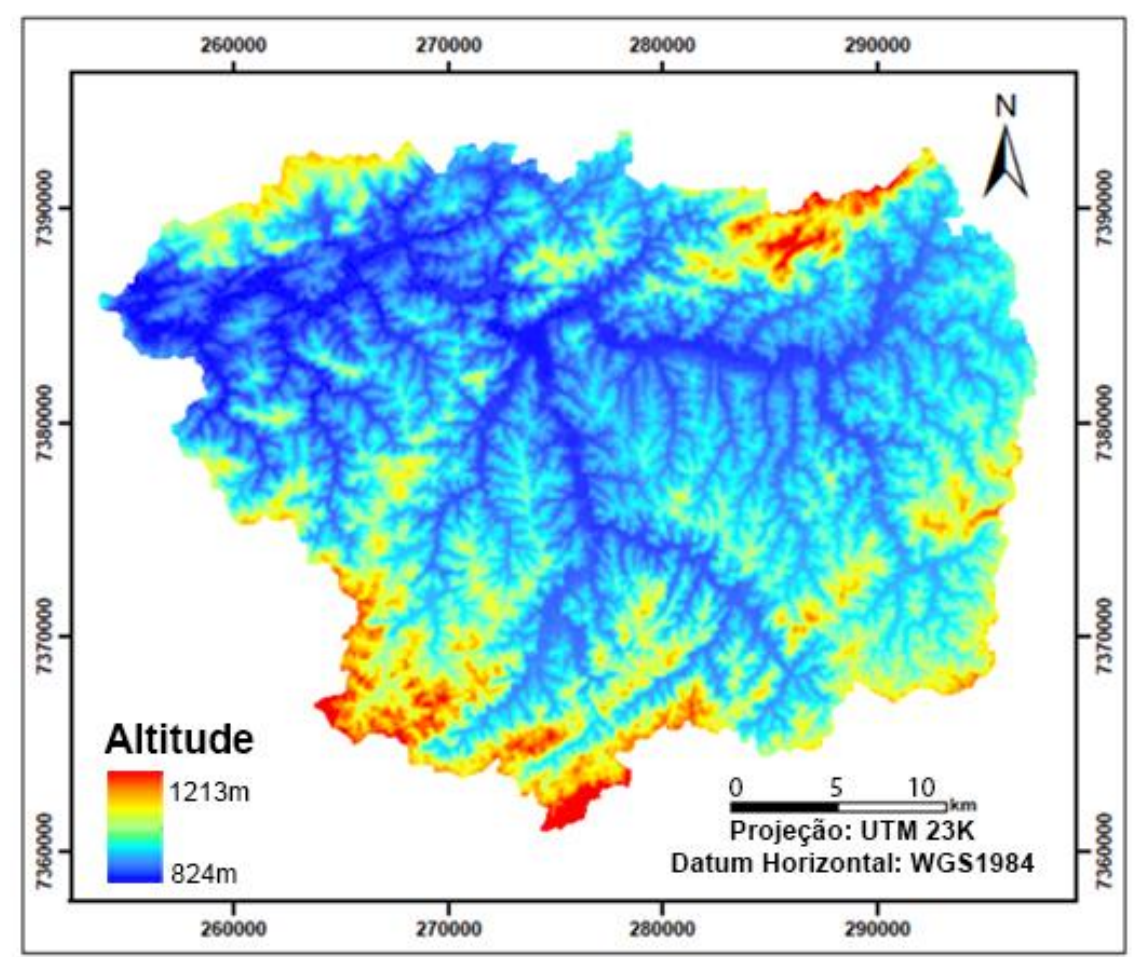

Figura 2: Altitude da APA Itupararanga, município de Sorocaba, São Paulo.

A partir da Figura 2 foi possível verificar que a altitude da APA Itupararanga apresentou variações entre 824 e 1.213 m, com uma variação média de 919 m. Segundo Castro (2007) [26], elevadas altitudes em bacias hidrográficas influenciam na quantidade de radiação solar recebida. Ainda, segundo os autores, a radiação influencia no balanço energético que, por sua vez, exerce influências diretas na temperatura, evapotranspiração e precipitação da bacia hidrográfica.

Estudos realizados por Oliveira et al. (2010) [27] também utilizaram imagens de SRTM para caracterização da Bacia Hidrográfica do Ribeirão Salobra, no município de Terenos (MS). Os autores compararam os resultados obtidos na caracterização morfométrica com dados do satélite SRTM, comparando-os com resultados obtidos a partir de cartas topográficas, e encontraram valores satisfatórios, concluindo que os estudos envolvendo o ambiente SIG e modelos digitais de elevação (MDE) podem ser utilizados em estudos envolvendo bacias hidrográficas.

Algumas características do relevo possibilitam inferir sobre a fragilidade da área, auxiliando na gestão e planejamento, dentre as quais encontra-se a declividade, pelo fato de influenciar diretamente nas características do relevo; assim, a declividade da APA Itupararanga é ilustrada na Figura 3. 


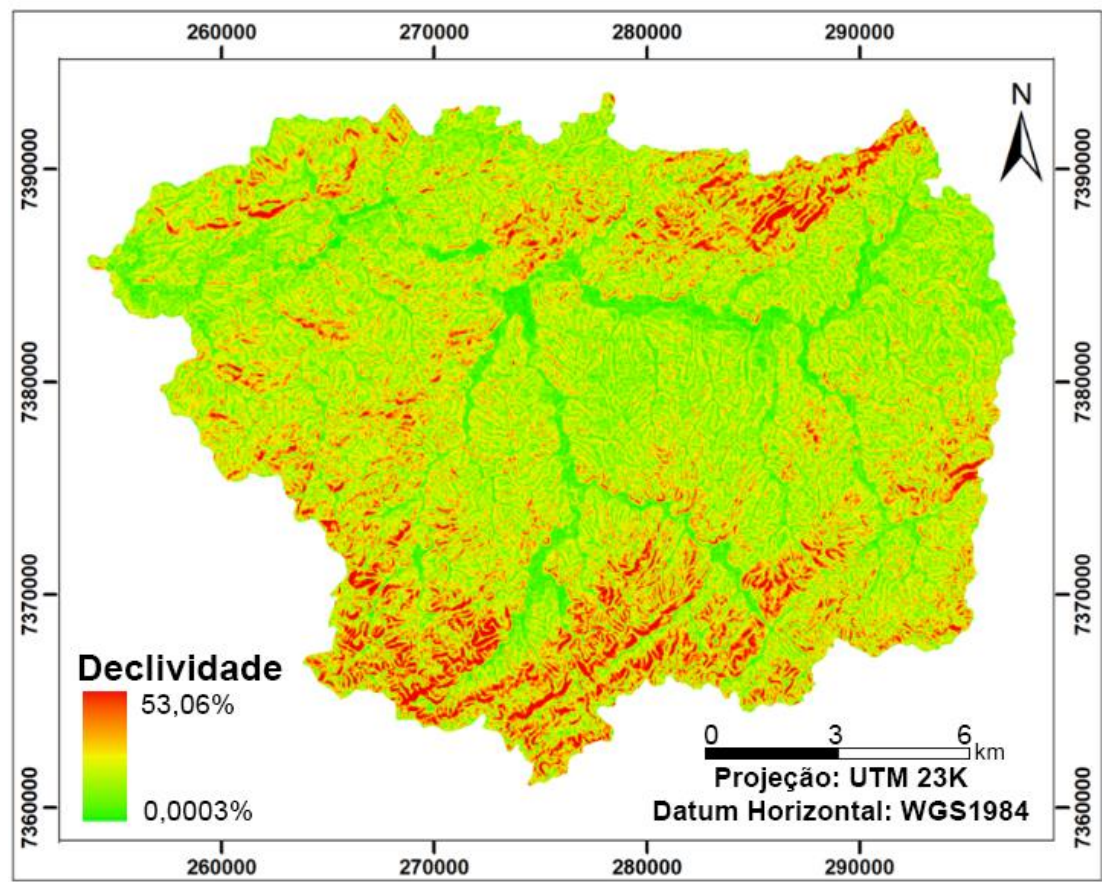

Figura 3: Declividade da APA Itupararanga, município de Sorocaba, São Paulo.

A declividade variou de 0 a $53 \%$, onde os valores próximos a 0 indicam a presença de corpos d'água, sendo as zonas mais baixas no relevo. As zonas com valores próximos a $53 \%$ indicam elevada declividade e podem acarretar danos aos recursos hídricos se não possuírem a vegetação preservada em virtude do arraste de sedimentos aos corpos d'água.

O conhecimento do relevo é uma ferramenta importante para delimitação do uso e ocupação do solo. Como exemplo, às áreas com declividade acima de 30\% [7] não são aptas para cultivos agrícolas devido ao potencial arraste de sedimentos que podem ser ocasionados pelos deflúvios pluviais [25].

A declividade exerce um papel importante no sentido de distribuição das águas provenientes do escoamento superficial, e, também, das águas subterrâneas. Ainda, o conhecimento de aspectos, tais como a declividade, contribui com informações relevantes para o planejamento, fornecendo diretrizes para as ações territoriais.

\subsection{Análise da Fragilidade Ambiental da APA Itupararanga}

O monitoramento ambiental possibilita a análise de áreas que possuem pré-disposição a sofrer impactos ocasionados tanto por fenômenos naturais como antrópicos [25]. Deste modo, o conhecimento dos fatores que podem ocasionar a degradação de determinadas áreas é fundamental, pois permite à mitigação dos impactos bem como sua prevenção.

A partir dos valores de declividade encontrados na área foi elaborado o mapa de Fragilidade da APA Itupararanga, permitindo a inferência das áreas mais vulneráveis de acordo com as características do relevo (Figura 4). 


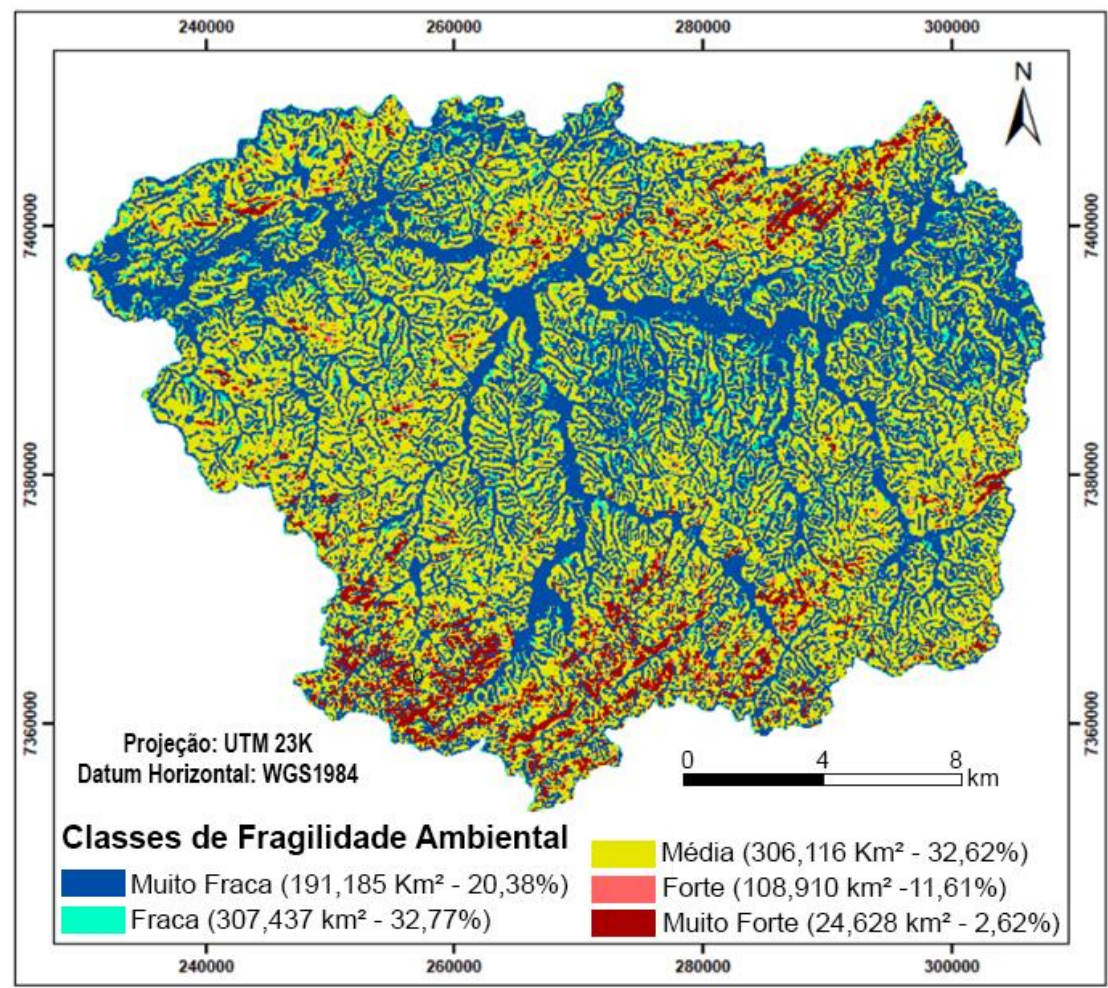

Figura 4: Classes de Fragilidade Ambiental da APA Itupararanga, município de Sorocaba, São Paulo.

As classes de fragilidade ambiental categorizadas como Muito Fraca e Fraca somaram uma área total de 498,622 $\mathrm{km}^{2}$, representando $53,15 \%$, enquanto as classes que preconizam um elevado grau de fragilidade ambiental totalizaram uma área de 439,654 km², representando 46,85\% da APA Itupararanga.

O conhecimento das áreas mais frágeis de um determinado local possibilita a execução de políticas de gestão específicas, sendo mais eficazes no sentido de conter a degradação ambiental local, além de promover a melhoria e maior efetividade das ações de restauração e recuperação ambiental. Ainda, de acordo com Li et al. (2006) [28], a vulnerabilidade de uma área está intrinsicamente relacionada com seus fatores bióticos e abióticos.

Segundo Tiecher et al. (2014) [29], o manejo inadequado do solo em áreas de plantios agrícolas, associados aos eventos de precipitação, assim como o cultivo em áreas com elevada fragilidade ambiental condicionadas pelo relevo e tipos de solos, constituem uma das principais fontes de aporte de sedimentos às redes de drenagem de uma bacia hidrográfica. Nesse sentido, o entendimento e conhecimento dos aspectos do ambiente são fundamentais para a criação de estratégias e práticas de cultivos sustentáveis.

A vegetação exerce fundamental importância ao que tange à proteção dos recursos hídricos. A cobertura vegetal é responsável pela interceptação de grande parte da água das chuvas e preservando os agregados dos solos [19]. No entanto, a substituição das áreas naturais pode acarretar diversos danos, desencadeando processos erosivos e, consequentemente, a deterioração da qualidade da água [30].

No tocante à manutenção dos recursos hídricos, as matas ciliares atuam como uma manta protetora das impurezas que podem aportar os cursos d'água. Devido seu papel fundamental na proteção dos recursos hídricos, às áreas de APP são protegidas por lei e seus usos são regulamentados pelo Novo Código Florestal [10].

Sendo assim, foram analisadas as áreas de APP da APA Itupararanga marginais aos cursos d'água (Figura 5). 


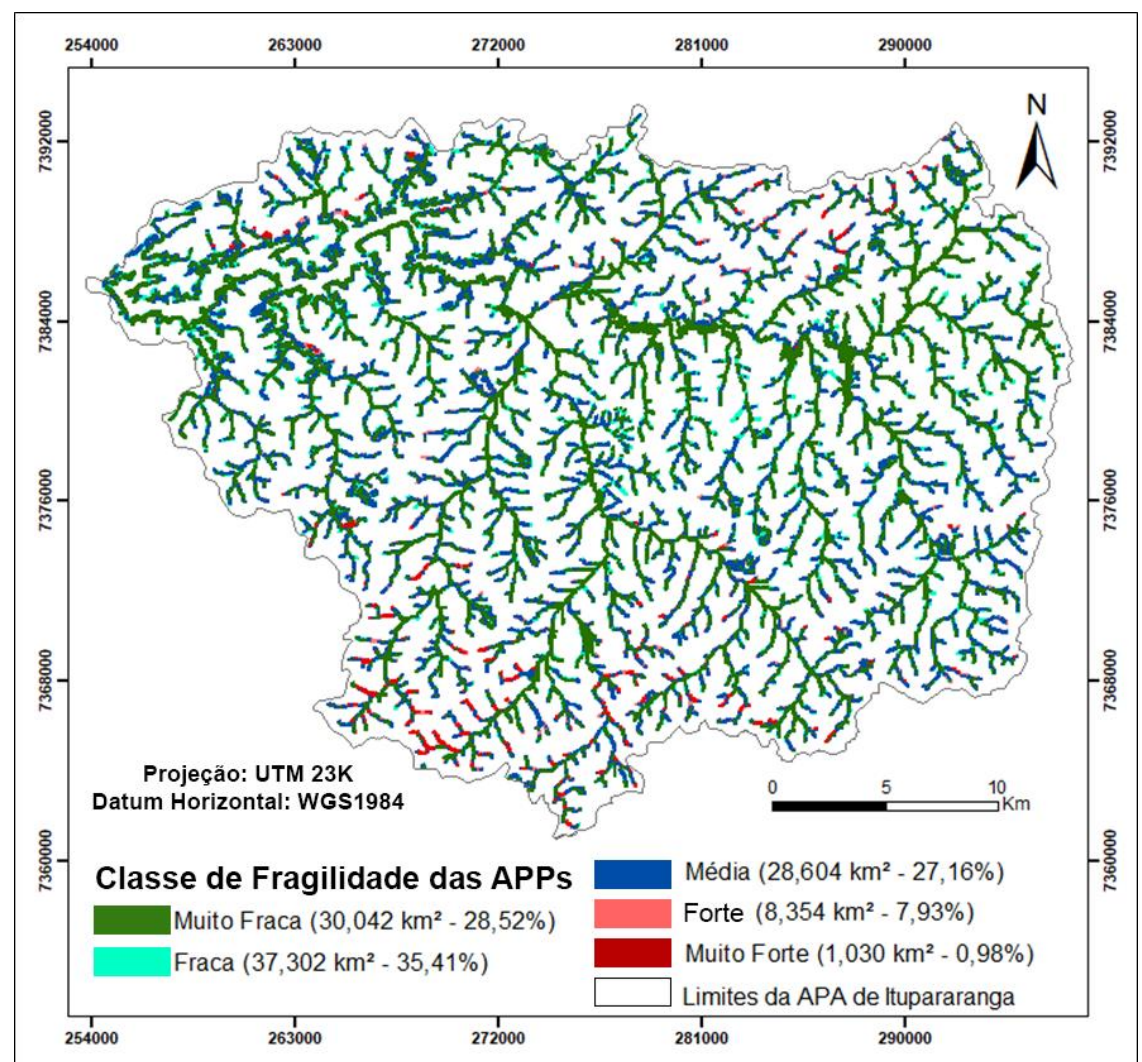

Figura 5: Classes de fragilidade das áreas de APP da APA Itupararanga, município de Sorocaba, São Paulo.

O estudo revelou que 63,93\% da APA Itupararanga possui pouca propensão à ocorrência de processos erosivos, totalizando uma área igual a $67,344 \mathrm{~km}^{2}$, considerando, somente, o fator associado à declividade do local. É importante salientar que a proteção dos recursos hídricos depende de diversos aspectos, principalmente os concernentes à proteção da vegetação ciliar.

A Figura 5 revelou que as áreas que compreendem a classificação muito fraca $\left(30,042 \mathrm{~km}^{2}\right) \mathrm{e}$ fraca $\left(37,302 \mathrm{~km}^{2}\right)$ representam as áreas com menor declividade, ou seja, as áreas que contemplam os cursos d'água. No entanto, as áreas classificadas como forte $\left(8,354 \mathrm{~km}^{2}\right)$ e muito forte $(1,030$ $\mathrm{km}^{2}$ ) apresentam maior concentração na região sul da área de estudo, representando um percentual de 8,91 da APA.

De acordo com Fonsêca et al. (2017) [31], os ambientes inseridos em áreas fragilizadas naturalmente, ao sofrerem perturbações antrópicas, não conseguem restabelecer seu estado de resiliência, pois para isso seria necessário um tempo que é incompatível com a escala imposta pelo modelo de desenvolvimento atual.

Estudos realizados por Reis e Costa (2017) [20] avaliaram o relevo como um dos aspectos abióticos da zona de amortecimento do Parque Estadual do Ibitipoca, em Minas Gerais. Os autores mapearam a vulnerabilidade das áreas de preservação permanente, utilizando técnicas de geoprocessamento que permitiram inferir sobre as áreas com maiores riscos a sofrerem perturbações antrópicas a partir do conhecimento do relevo, tipo de solo e usos do solo presentes na zona de amortecimento da Unidade de Conservação; deste modo, as áreas mais suscetíveis representaram $78 \%$ do estudo, resultado bastante crítico, visto que as áreas de APP são protegidas por lei e deveriam ter seu uso e ocupação restritos.

\subsection{Uso do solo da APA Itupararanga}

O uso do solo traz diversas implicações na qualidade dos corpos hídricos. Assim, o uso da terra e às atividades antrópicas a elas relacionadas podem comprometer a qualidade bem como a disponibilidade de água tanto para o consumo humano quanto para a biota. A Figura 6 ilustra o uso do solo da APA Itupararanga. 


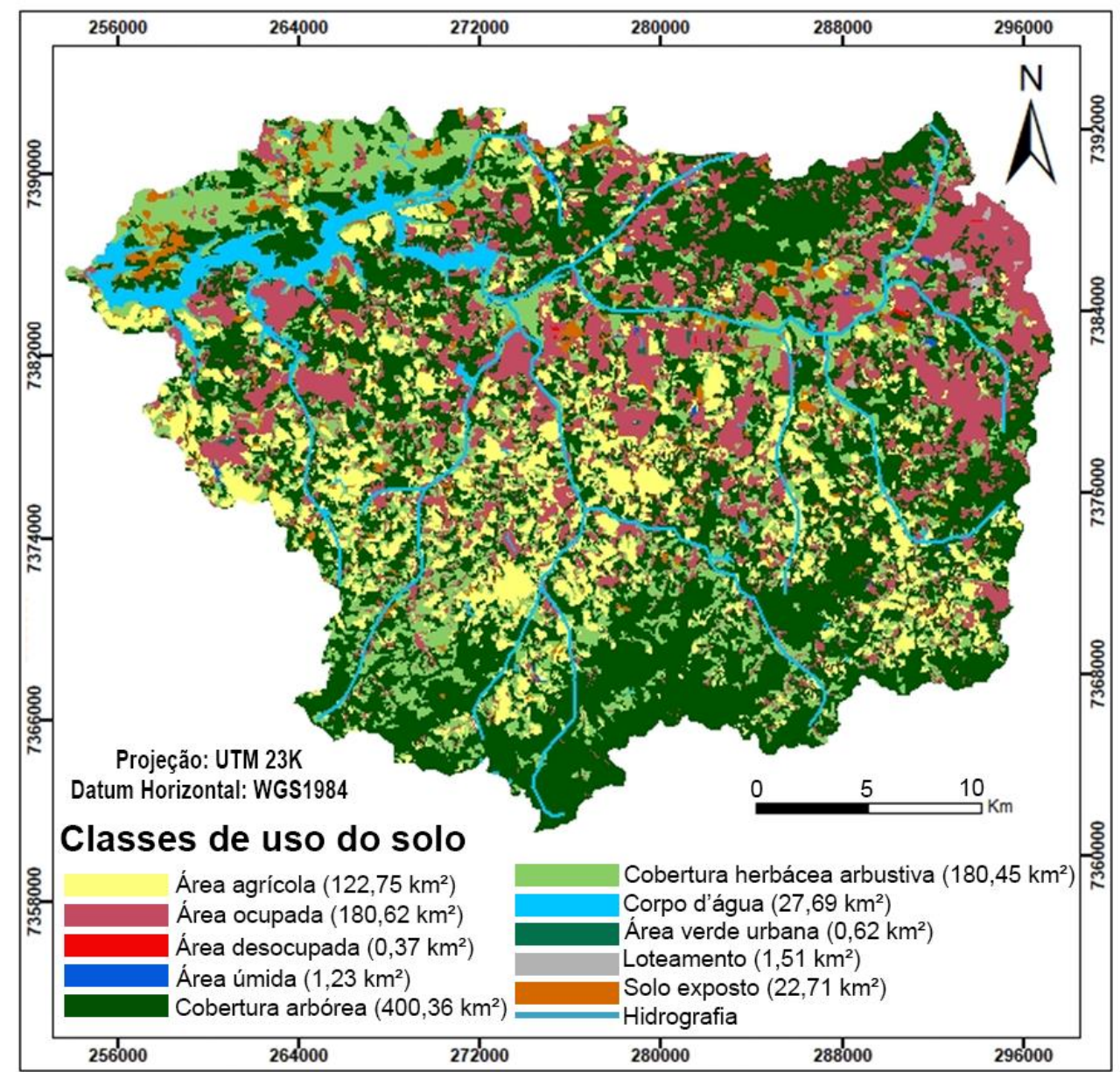

Figura 6: Classes de usos do solo da APA Itupararanga, município de Sorocaba, São Paulo.

Os resultados obtidos na análise do uso e ocupação (Figura 6) demonstraram que as classes agrícolas possuem uma área de $122,75 \mathrm{~km}^{2}$, sendo distribuídas por toda a extensão da APA. No entanto, as maiores porções estão localizadas na faixa central, principalmente nas sub-bacias do rio Una, com uma área de $15,87 \mathrm{~km}^{2}$ e Sorocabuçu, com 30,61 km², bem como nas áreas próximas ao reservatório, com $33,73 \mathrm{~km}^{2}$. Entretanto, a sub-bacia do rio Sorocamirim foi a que apresentou a maior extensão de áreas agrícolas, com $39,79 \mathrm{~km}^{2}$.

Estudos realizados por Tiecher et al. (2014) [29] analisaram as fontes de sedimentos de uma bacia hidrográfica de cabeceira com predomínio agrícola, localizada no município de Júlio de Castilhos (RS), e verificaram que uma das principais causas de poluição difusa em bacias hidrográficas é proveniente do arraste de sedimentos de fontes agrícolas, devido à ausência de planejamento e técnicas adequadas de manejo do solo em áreas de lavouras.

As áreas ocupadas apresentaram uma extensão de $180,62 \mathrm{~km}^{2}$, estendendo-se na faixa central da APA com maior adensamento a nordeste, onde se localiza o município de Vargem Grande Paulista, que, por sua vez, possui a maior extensão territorial inserida na APA, com 85,4\%.

Os resultados obtidos do uso e ocupação demonstraram que as classes agrícolas possuem uma área de $122,75 \mathrm{~km}^{2}$, sendo distribuídas por toda a extensão da APA. No entanto, as maiores porções estão localizadas na faixa central, principalmente nas sub-bacias do rio Una.

As áreas com cobertura arbórea apresentaram uma extensão de $400,36 \mathrm{~km}^{2}$, distribuídas de forma fragmentada em toda a extensão da APA. As zonas que apresentaram cobertura vegetal mais contínua estão situadas próximas aos limites inferiores da APA, na área instituída pelo Plano de Manejo [24], como Zona de Conservação da Biodiversidade. Essa faixa mais acentuada de cobertura arbórea está inserida em uma região de alta declividade. Ainda, a extensa faixa de cobertura arbórea identificadas ao Sul da APA, segundo o Plano de Manejo [24], constitui um corredor ecológico conectado ao Parque Estadual de Jurupará. De acordo com Oliveira et al. 
(2016) [32], os corredores ecológicos são imprescindíveis ao que tange à preservação das espécies e manutenção da flora e fauna, possibilitando a troca genética e, consequente, perpetuação das espécies.

As áreas marginais ao reservatório apresentaram uma considerável faixa de cobertura arbórea; entretanto, é importante ressaltar que a cobertura arbórea mapeada no estudo não contemplou a distinção das diferentes tipologias florestais presentes na área; sendo assim, a cobertura arbórea da área apresenta vastas áreas de plantios de silvicultura.

As áreas com coberturas herbácea-arbustivas apresentaram $180,45 \mathrm{~km}^{2}$ de extensão e contemplam as formações de pastos, gramíneas e espécies forrageiras. As maiores extensões dessa classe de uso foram encontradas na sub-bacia do reservatório de Itupararanga, com faixas mais acentuadas observadas na parte superior direita do reservatório.

As classes de solo exposto apresentaram uma significativa extensão, abrangendo uma área de $22,71 \mathrm{~km}^{2}$. O solo exposto apresenta um risco iminente aos corpos d'água, uma vez que fica suscetível à erosão hídrica desencadeada pelas chuvas.

O potencial de degradação da qualidade ambiental da APA se dá pela interação de diversos fatores que puderam ser identificados no presente estudo, principalmente os concernentes ao uso e ocupação do solo na APA Itupararanga.

\subsection{Classes de Risco das áreas de APP da APA Itupararanga}

Tendo em vista a importância das matas ciliares, foram analisadas as áreas de APP da APA Itupararanga marginais aos cursos d'água, de modo que fosse obtido um painel geral das classes de riscos da área (Figura 7).

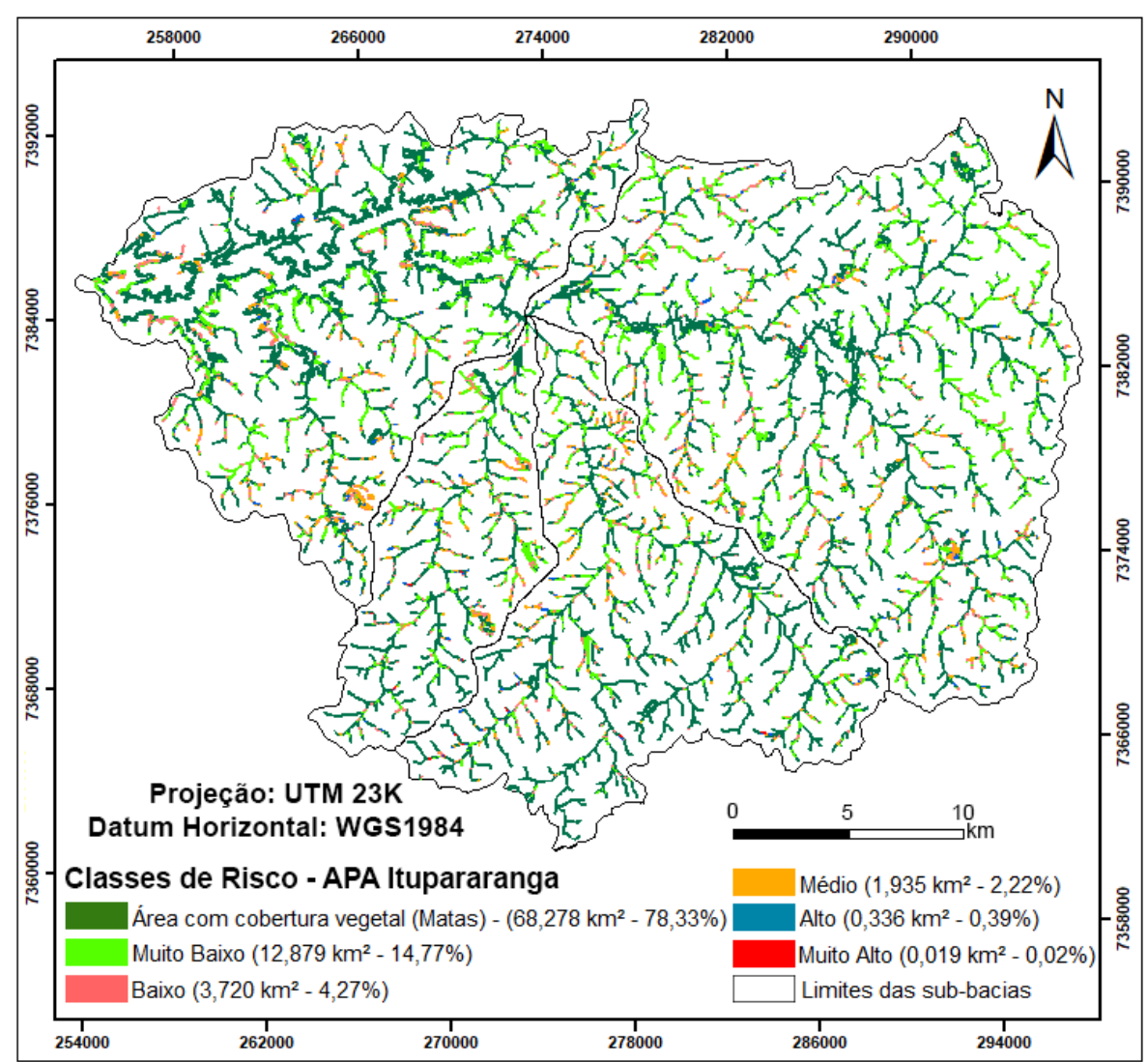

Figura 7: Classes de risco das áreas APP marginais aos cursos de água da APA Itupararanga, município de Sorocaba, São Paulo.

A partir da análise das classes de risco da APA Itupararanga (Figura 7) foi possível inferir que $78,33 \%$ da APA apresenta cobertura vegetal, o que corresponde a uma área de $68,278 \mathrm{~km}^{2}$, sendo que os riscos classificados como Muito Baixo e Baixo representam 19,04\%, contemplando uma 
área de 16,60 $\mathrm{km}^{2}$, enquanto os riscos classificados como Médio, Alto e Muito Alto totalizaram $2,63 \%$ e uma área total de $2,29 \mathrm{~km}^{2}$.

Com vistas ao melhoramento da visualização das áreas de preservação permanente foi realizada a ampliação da escala real (1:250.000) em 1,5\%. Ainda, para melhorar a interpretação e acurácia dos resultados, as classes de risco das APPs das sub-bacias da APA Itupararanga foram analisadas individualmente (Figura 8).

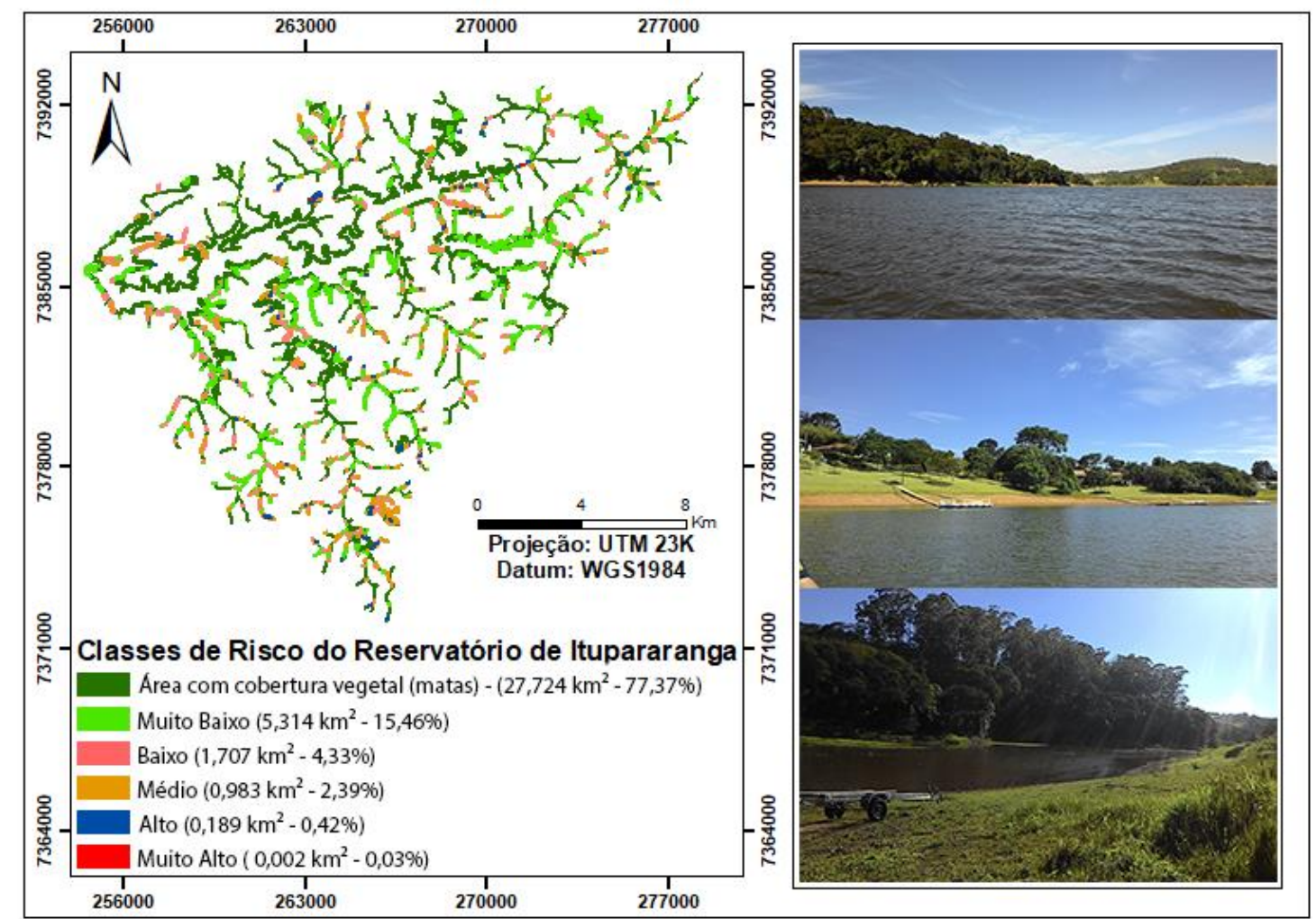

Figura 8. Classes de risco das áreas de APP do reservatório de Itupararanga, município de Sorocaba, São Paulo.

A partir da Figura 8 foi possível inferir que as APP possuem 77,37\% de cobertura vegetal, com uma área equivalente a $27,724 \mathrm{~km}^{2}$. Os riscos contemplados nas classes Muito Baixo e Baixo corresponderam a uma área igual a $7,021 \mathrm{~km}^{2}$ e representação de $19,79 \%$. Já os riscos considerados Médio, Alto e Muito Alto totalizaram 2,84\%, com uma área de $1,174 \mathrm{~km}^{2} \mathrm{de}$ extensão.

A partir da inspeção in situ foi possível observar os diferentes usos às margens do reservatório, dentre os quais se destacam as coberturas herbácea-arbustivas; plantios de espécies exóticas por meio de silvicultura; fragmentos florestais preservados; áreas de pastagem; cultivos agrícolas e áreas ocupadas por condomínios residenciais. No entanto, a vegetação não está preservada em grande parte do reservatório, visto que este apresenta vastas áreas de plantios de monocultura de pinus (Pinus elliottii Engelm) e eucalipto (Eucalyptus globulus), atividade esta que apresenta grande representatividade na área, conforme já foi relatado nos estudos de Salles et al. (2008) [23] e no Plano de Manejo da APA [24].

Contudo, apesar desta vegetação cumprir algumas funções, tais como a preservação da integridade do solo, apresentam pouca diversidade biológica, o que impacta diretamente na diversidade da fauna e flora locais.

Apesar dos riscos mais significativos terem apresentado um percentual relativamente baixo, é necessária uma atenção especial às possíveis alterações na qualidade da água, principalmente no tocante aos níveis de trofia do reservatório encontrados por alguns autores, como Frascareli et al. (2015) [33] e Rosa et al. (2015) [34], que identificaram elevados valores de nutrientes, como nitrogênio total e fósforo total aportados no reservatório. 
Estudos realizados por Taniwaki et al. (2011) [35] e (2013) [36] também encontraram impactos na qualidade e genotoxicidade da água advindos dos diversos usos do seu entorno, sendo identificados altos níveis tróficos no reservatório, atribuídos, principalmente, pelas atividades agrícolas e ocupação urbana na Bacia Hidrográfica do Alto Sorocaba.

$\mathrm{O}$ rio Una é um dos principais cursos d'água formadores do reservatório de Itupararanga. Nesse sentido, a Figura 9 ilustra as classes de risco das APPs marginais ao rio.

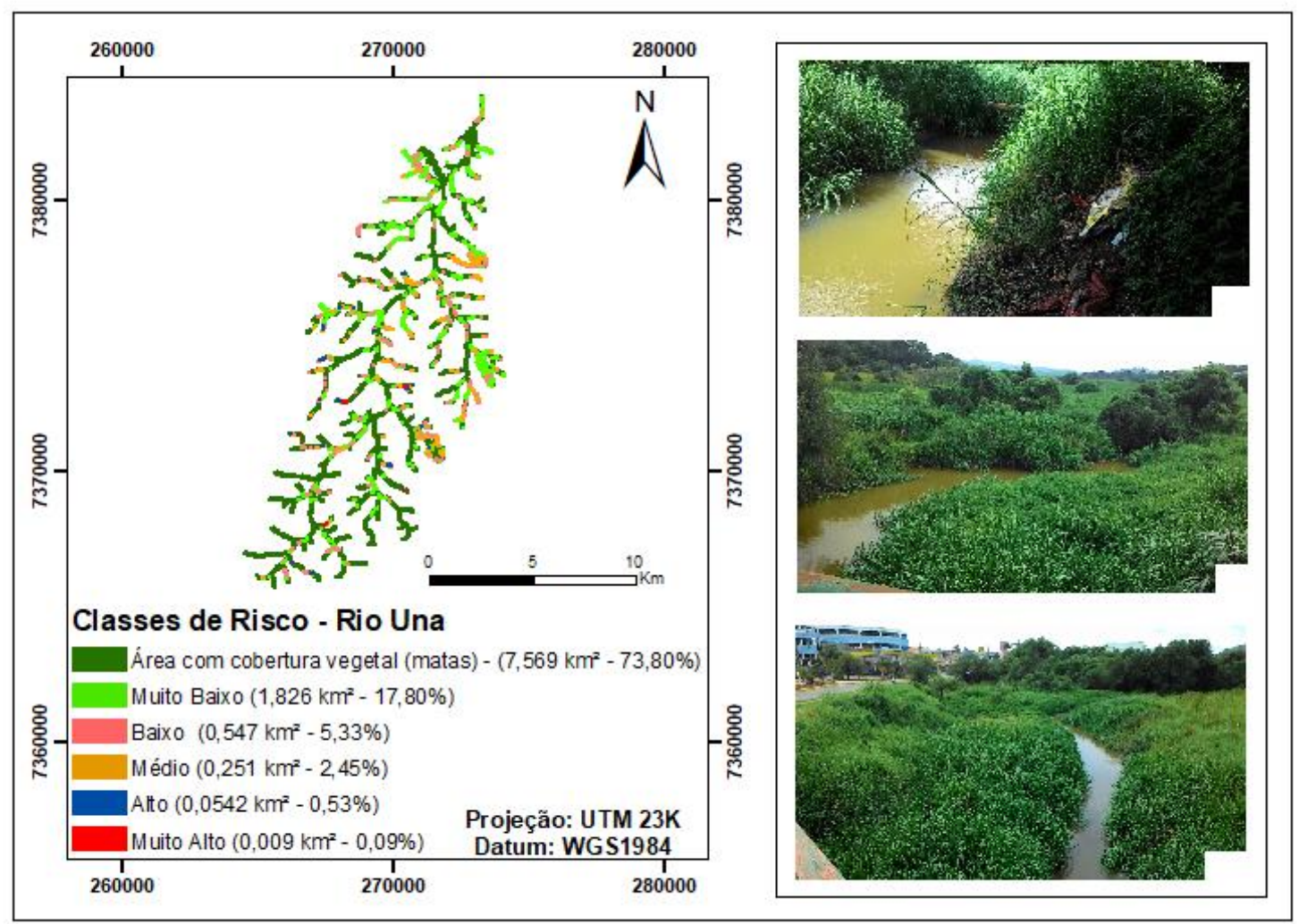

Figura 1. Classes de risco das áreas de APP do rio Una

Os resultados apresentados na Figura 9 demonstraram que 73,80\% da sub-bacia apresenta cobertura vegetal. Os riscos classificados como Muito Baixo e Baixo apresentaram 23,13\%, abrangendo uma extensão de 2,373 $\mathrm{km}^{2}$. As áreas classificadas com riscos Médio, Alto e Muito Alto totalizaram $3,07 \%$ da sub-bacia, com uma área equivalente a $0,3142 \mathrm{~km}^{2}$.

Ainda, a partir das imagens da Figura 9 foi possível verificar que as margens do curso d'água encontram-se revestidas por cobertura vegetal, com predominância de gramíneas em alguns trechos. Também foi verificada a presença de indivíduos arbóreos distribuídos de forma esparsa e, sobretudo, que o rio Una está inserido em uma zona urbana do município de Ibiúna. Durante a inspeção in situ foi possível verificar a presença de lixo em diversos trechos às margens do rio. O estudo também revelou que a sub-bacia do rio Una possui grande parte de sua extensão com presença de cobertura vegetal, e por essa razão, apresenta riscos relativamente baixos.

A análise espacial das classes de risco das áreas de APP da sub-bacia do rio Sorocamirim foi ilustrada na Figura 10. 


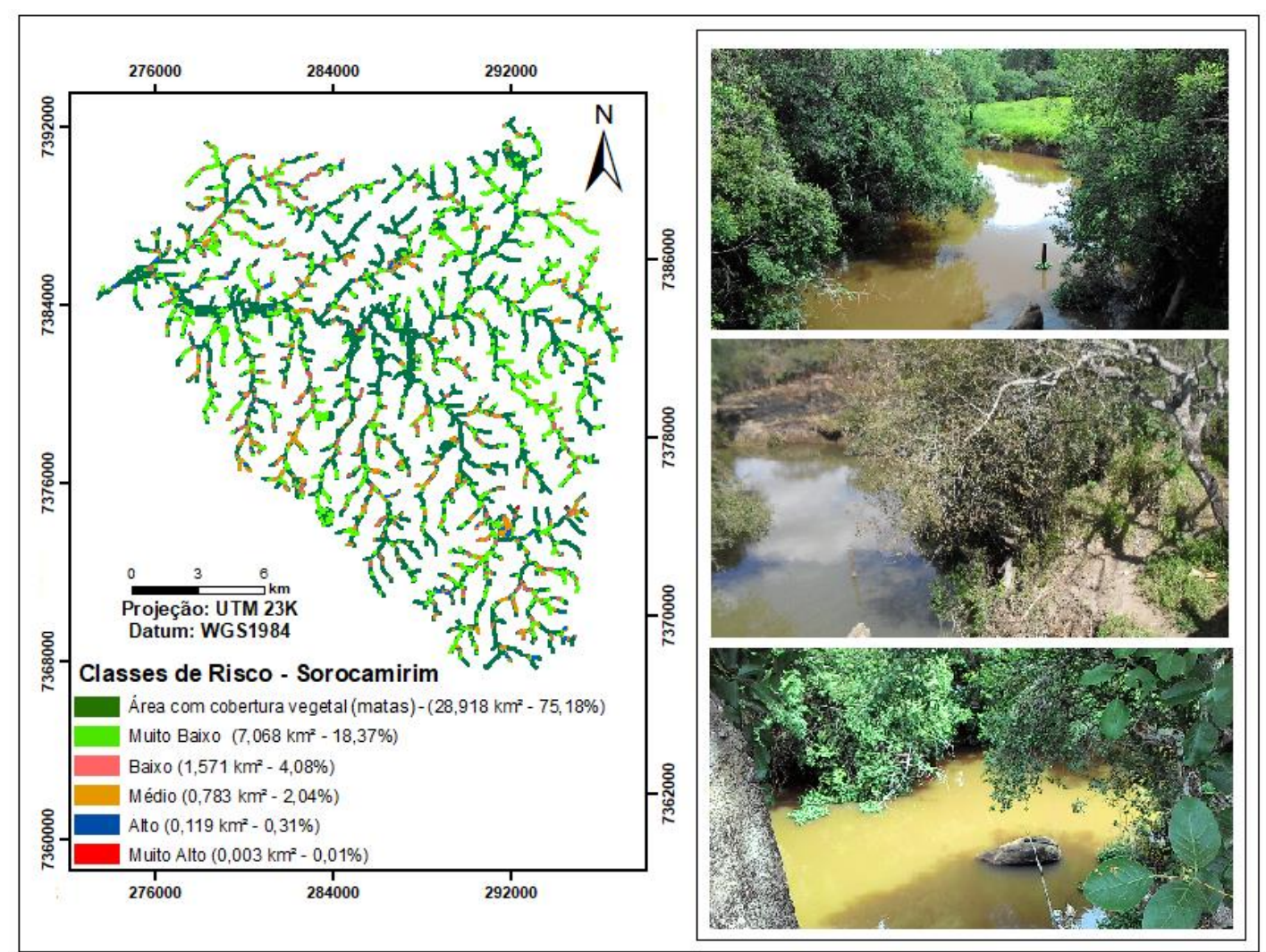

Figura 2. Classes de Risco das Áreas de APP do rio Sorocamirim

A partir da Figura 10 foi possível determinar que as áreas de APP marginais aos cursos de água da sub-bacia do Sorocamirim possuem $75,18 \%$ de cobertura vegetal, totalizando uma área de $28,918 \mathrm{~km}^{2}$. As áreas de APP situadas em zonas de risco Muito Baixo e Baixo totalizaram $22,45 \%$ da área e uma extensão de $8,639 \mathrm{~km}^{2}$, já os riscos inseridos nas classes Médio, Alto e Muito alto totalizaram 2,36\% do estudo, com uma área equivalente a $0,932 \mathrm{~km}^{2}$.

As queimadas observadas às margens do rio Sorocamirim podem desencadear uma série de impactos negativos caso seja realizada de forma contínua, podendo levar a perda da capacidade produtiva dos solos, de espécies florísticas e biodiversidade da fauna.

A partir das visitas in situ foi verificado que às margens do curso d'água apresentam aspectos bastantes distintos em relação à sazonalidade. Tal fato possui extrema relevância no estudo dos corpos hídricos, pois a sazonalidade interfere de modo bastante drástico no regime dos rios. Nesse sentido, o monitoramento das áreas de APP é necessário para o acompanhamento das possíveis degradações ocasionadas aos recursos hídricos.

As classes de risco da sub-bacia do rio Sorocabuçu foram representadas na Figura 11. 


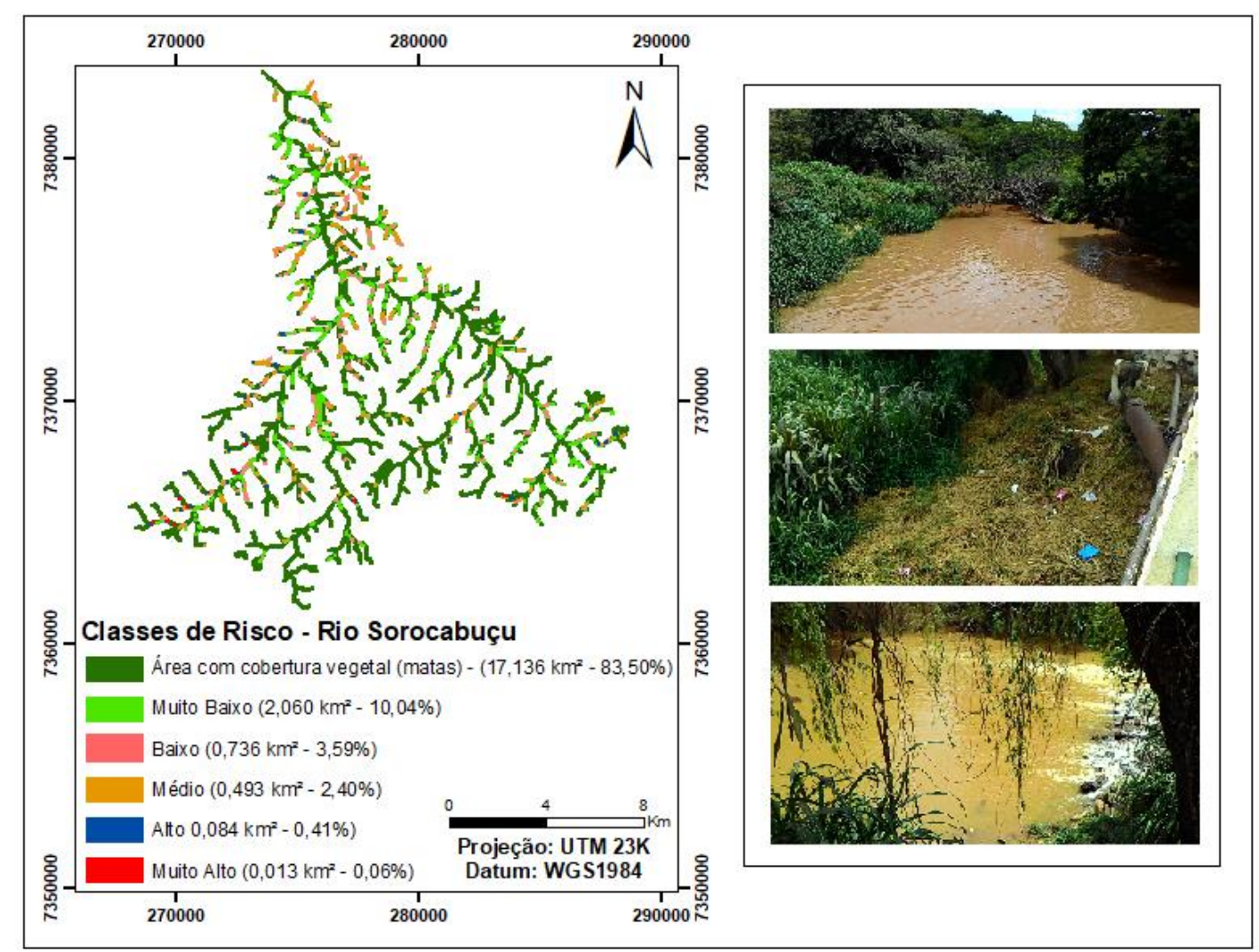

Figura 3. Classes de risco das APPs da sub-bacia do rio Sorocabuçu

A partir da Figura 11 foi possível inferir que 83,50\% das APPs que compreendem a sub-bacia do rio Sorocabuçu apresentam cobertura vegetal, abrangendo uma extensão de $17,14 \mathrm{~km}^{2}$. Os riscos respectivos às classes Muito Baixo e Baixo compreenderam, respectivamente, 10,04\% e 3,59\%. Já os riscos atribuídos às classes Médio, Alto e Muito Alto, totalizaram 2,87\%, com uma extensão de $0,59 \mathrm{~km}^{2}$ das APPs da sub-bacia.

Na Figura 11 são evidenciados os principais aspectos das matas ciliares verificados in situ. $\mathrm{O}$ trecho do rio Sorocabuçu amostrado demonstrou um bom estado de conservação da vegetação ripária, com a presença de diversos indivíduos arbóreos.

Contudo, também foi possível observar um trecho da APP com um aspecto menos preservado, contendo lixo e reflexos das atividades antrópicas locais, além de trechos em processo inicial de erosão das margens. Os processos erosivos concernentes às margens dos rios é uma das interferências inerentes à urbanização de uma bacia hidrográfica fortemente antropizada, uma vez que as áreas impermeabilizadas aumentam a velocidade do fluxo de água que chegam à calha fluvial [11].

Os autores Garcia e Barbosa (2017) [37] associaram a ocupação indevida das áreas de APP a problemas de saneamento básico ocasionados pelo lançamento de efluentes e pelo mau uso dessas áreas. Enquanto Fonsêca et al. (2017) [31] ressaltaram que os ambientes inseridos em áreas fragilizadas, ao sofrerem perturbações antrópicas, não conseguem restabelecer seu estado de resiliência, pois para isso seria necessário um tempo que é incompatível com a escala imposta pelo modelo de desenvolvimento antrópico atual.

É importante salientar que o presente estudo tratou apenas de analisar se as áreas de preservação permanente marginais aos cursos de água das sub-bacias inseridas na APA Itupararanga se encontram revestidas por cobertura vegetal, sem considerar as fitofisionomias características dessas áreas. $\mathrm{O}$ fato de possuir cobertura vegetal confere às margens uma proteção contra os processos erosivos resultantes do escoamento superficial e do aporte de sedimentos aos corpos d'água. Contudo, a variabilidade florística da vegetação também é de suma importância para a fauna e organismos aquáticos, e, também, devem ser consideradas em futuros estudos, de modo a caracterizar as fitofisionomias ripárias presentes na APA. 
Embora os riscos das APPs categorizados como Médio, Alto e Muito Alto tenham apresentado valores de área e percentual relativamente baixos, é importante salientar que as visitas in situ realizadas durante o estudo revelaram um cenário de degradação em todas as sub-bacias analisadas, compreendendo, principalmente, feições erosivas representadas por sulcos e ravinas nas margens dos rios Una, Sorocabuçu e Sorocamirim. Os processos erosivos identificados estão intimamente relacionados à ausência de vegetação nessas áreas; ainda, em alguns trechos, também foi constatada uma elevada carga de lixo disposto nas margens, paisagem essa que se reverbera na maior parte das áreas marginais aos cursos de água dos estados brasileiros.

Os resultados obtidos via sensoriamento remoto corroboraram com o risco potencial verificado em campo, uma vez que a APA Itupararanga está localizada em uma região geomorfologicamente composta por morros, escarpas e serras que possuem uma fragilidade intrínseca devido à alta declividade constatada no presente estudo, sendo que esses fatores, somados, resultam em uma alta suscetibilidade a deslizamentos de terras, devendo, portanto, haver uma fiscalização efetiva que garanta os preceitos de seus devidos usos.

A sub-bacia com maior proeminência em ocasionar prejuízos aos recursos hídricos da APA Itupararanga devido aos riscos identificados foi a do rio Una, sendo, por essa razão, a sub-bacia prioritária para ações de recuperação e conservação da vegetação.

\section{CONCLUSÃO}

Visto a importância da compreensão dos aspectos que podem contribuir com a degradação bem como o comprometimento da integridade das florestas ripárias, o presente estudo possibilitou uma análise das áreas de APP marginais aos cursos de água da APA Itupararanga de forma pormenorizada, dando início a um importante trabalho de monitoramento das áreas ciliares da APA que é primordial para a manutenção da qualidade da água do reservatório de Itupararanga, uma vez que os impactos causados pelo uso inadequado das margens comprometem a qualidade e a disponibilidade de água desse importante reservatório de abastecimento público para região de Sorocaba.

As observações in situ associadas às análises em ambiente SIG proporcionaram uma caracterização do estado atual de preservação das matas ciliares da APA Itupararanga e os riscos associados aos diversos usos do solo presentes no seu entorno. A sobreposição de diferentes planos de informação permitiu inferir sobre os riscos presentes na APA em razão dos aspectos geomorfológicos, associados ao relevo, assim como aos diferentes usos do solo no entorno dos cursos de água.

A metodologia utilizada apresentou bons resultados ao que tange o diagnóstico dos riscos inerentes às matas ciliares, podendo ser replicado em outras bacias hidrográficas, partindo da premissa da importância das matas ciliares como mantenedoras da qualidade das águas, da integridade dos solos e das funções ecológicas que propiciam suporte a vida silvestre, sendo possível orientar visitas/trabalhos de campos para averiguação do estado ambiental em que se encontram as áreas identificadas com alto risco de carreamento de sedimentos, consequentemente, áreas com potencial de alteração da qualidade da água.

Essa proposta metodológica permite aos gestores públicos e interessados na questão de restauração ecológica priorizar as áreas que necessitam de recomposição da vegetação com o propósito de proteção aos recursos hídricos, visto que os aspectos de uso e ocupação do solo associados às características físicas da área são fundamentais para avaliar fragilidade ambiental dessas áreas e servem de parâmetros para intervenções antrópicas visando à atenuação dessa fragilidade, sendo possível identificar a bacia hidrográfica do rio Una como a de maior prioridade para recomposição da vegetação devido à presença de muitos sulcos e ravinamentos nas áreas marginas aos cursos de água e ausência de vegetação.

As classes de riscos apresentadas no estudo indicaram que as áreas de APP da APA Itupararanga sugerem reflexos da elevada antropização, sendo necessárias constantes fiscalizações e ações que visem minimizar as atividades que causam a degradação das florestas ciliares num âmbito geral. Todavia, o estudo proporciona um importante subsídio para as ações 
futuras que objetivem à conservação dos recursos naturais da APA Itupararanga, auxiliando na gestão e planejamento por parte dos órgãos gestores da Unidade de Conservação.

\section{REFERÊNCIAS BIBLIOGRÁFICAS}

1. Tabarelli M, Pinto LP, Silva JMC, Hirota MM, Bedê LC. Desafios e oportunidades para a conservação da biodiversidade na Mata Atlântica brasileira. Megadiversidade. 2005 Jul;1:132-138.

2. Manfredini, FN, Guandique MEG, Rosa AH. A história ambiental de Sorocaba. Sorocaba: UnespCâmpus Experimental de Sorocaba; 2015. 180 p.

3. Reis $\mathrm{CH}$, Amorim RR, Ferreira C. Caracterização do uso e ocupação das terras de áreas com risco à inundação em Cardoso Moreira e Italva, Rio de Janeiro. Caminhos de Geografia. 2015 Set;16(55):1-17.

4. Ab'Saber AN. Matas ciliares: conservação e recuperação. 2nd ed. Edusp, Fapesp; 2004. O suporte ecológico das florestas beiradeiras (ciliares); p. 15-25.

5. Tundisi JG, Tundisi TM. Impactos potenciais das alterações do Código Florestal nos recursos hídricos. Biota Neotropica. 2010;10(4).

6. Tambosi LR, Vidal MM, Ferraz SFDB, Metzger JP. Funções eco-hidrológicas das florestas nativas e o Código Florestal. Estudos avançados. 2015 Maio;29(84):151-162, doi:10.1590/S010340142015000200010.

7. Ross JLS. Análise Empírica da Fragilidade dos Ambientes Naturais e Antropizados. Revista do Departamento de Geografia. 1994;8:63-74, doi:10.7154/RDG.1994.0008.0006.

8. Tricart J. Ecodinâmica. Rio de Janeiro: Supren/IBGE; 1977. 97p.

9. Brasil. Lei ${ }^{\circ}$. 9.433, de 8 de janeiro de 1997. Institui a Política Nacional de Recursos Hídricos, Cria o Sistema Nacional de Gerenciamento de Recursos Hídricos, e dá outras providências. Diário Oficial da União, 1997.

10. Brasil. Lei $\mathrm{n}^{\circ}$. 12.651, de 25 de maio de 2012. Dispõe sobre a proteção da vegetação nativa. Diário Oficial da República Federativa do Brasil. Brasília: DF; 2012.

11. Silva DCC, Albuquerque Filho, JL, Oliveira RA, Lourenço RW. Metodologia para análise do potencial de degradação dos recursos hídricos em bacias hidrográficas. Caderno de Geografia. 2017 Jan;27(50):455-466, doi:10.5752/p.2318-2962.2017v27n50p455.

12. Sales JCA, Silva DCC, Bertagna LFTDR, Lourenço RW. Environmental impact assessment caused by the timeline changes from the land use and vegetation cover using the model of Markov Chains. Ciência e Natura. 2016;38(1):115-124, doi:10.5902/2179460X1864.

13. Andrade RG, Rodrigues CAG, Sanches IDA, Torresan FE, Quartaroli CF. Uso de técnicas de sensoriamento remoto na detecção de processos de degradação de pastagens. Engenharia na Agricultura. 2013;21(3):234-243, doi:10.13083/reveng.v21i3.368.

14. Menezes DJ, Trentin, R. Mapeamento do uso do solo na Bacia Hidrográfica do rio Quaraí sob a perspectiva da orizicultura e a demanda de água associada nas porções brasileira e uruguaia. Ciência e Natura. 2014 Set;36(3):385-392, doi:10.5902/2179460X12277.

15. Bacani VM, Sakamoto AY, Luchiari A, Quénol H. Sensoriamento remoto e SIG aplicados à avaliação da fragilidade ambiental de bacia hidrográfica. Mercator-Revista de Geografia da UFC. 2015 Mai:14(2):119-135, doi:10.4215/RM2015.1402.0008

16. Gouveia RGL, Galvanin EAS, Neves SMAS, Neves RJ. Análise da fragilidade ambiental na bacia do rio Queima-Pé, Tangará da Serra, MT. Pesquisas em Geociências. 2015;42(2):131-140, doi:10.22456/1807-9806.78115

17. Queiroz Junior VS, Cabral JBP, Rocha IR, Barcelos AA. Uso de geotecnologias na caracterização da fragilidade ambiental da Bacia da UHE Foz do Rio Claro (GO). Revista Internacional de Ciencia y Tecnología de la Información Geográfica. 2015;15:193-212.

18. Gamarra RM, Teixeira-Gamarra MC, Carrijo MGG, Paranhos Filho AC. Uso do NDVI na análise da estrutura da vegetação e efetividade da proteção de Unidade de Conservação no Cerrado. Raega-O Espaço Geográfico em Análise. 2016 Ago;37:307-332, doi:10.5380/raega.v37i0.42454.

19. Mendes TA, Mariano JV, Marques PHG, Santos LPS. Diagnóstico ambiental da área de preservação permanente da nascente do córrego almeida utilizando ferramenta de geoprocessamento (Aparecida de Goiânia-GO). Ciência e Natura. 2016 Set;38(3):1331-1345, doi: 10.5902/2179460X22867.

20. Reis TE, Costa, VC. Análise da vulnerabilidade na zona de amortecimento do Parque Estadual do Ibitipoca (MG), com o uso de SIG. Geosul. 2017;32(63):77-96, doi:10.5007/2177$5230.2017 \mathrm{v} 32 \mathrm{n} 63 \mathrm{p} 77$.

21. Simonetti VC, Silva DCC, Oliveira RA, Sabonaro DZ, Rosa AH. Análise da suscetibilidade do solo a processos erosivos do Parque Natural Municipal Corredores de Biodiversidade (PNMCBIO) de 
Sorocaba (SP). Raega - O Espaço Geográfico em Análise. 2018 Mai;44:169-180, doi:10.5380/raega.v44i0.48838

22. Pedrazzi FJM, Conceição FT, Sardinha DS, Moschini-Carlos V, Pompêo M. Avaliação da qualidade da água no reservatório de Itupararanga, Bacia do Alto Sorocaba (SP). Revista Geociências. 2014;33(1):26-38.

23. Salles MHD, Conceição FT, Angelucci VA, Sia R, Pedrazzi FJM, Carra TA, Navarro GRB. Avaliação Simplificada de Impactos Ambientais na Bacia do Alto Sorocaba (SP). Revista de estudos ambientais. 2008 Jan;10(1):6-20, doi:10.7867/1983-1501.2008v10n1p6-20.

24. Fundação Florestal. Plano de Manejo da APA Itupararanga. Secretaria de Estado de Meio Ambiente. 2010.

25. Silva DCC, Sales JCA, Albuquerque Filho JL, Lourenço RW. Caracterização morfométrica e suas implicações no acúmulo de sedimentos em reservatórios: O caso da Represa Hedberg, Iperó/SP. RaegaO Espaço Geográfico em Análise. 2016 Abr;36:225-245, doi:10.5380/raega.v36i0.42324.

26. Castro PS. Recuperação e conservação de nascentes. Viçosa: Centro de Produções Técnicas; 2007. $272 p$.

27. Oliveira PTS, Alves Sobrinho T, Steffen JL, Rodrigues DBB. Caracterização morfométrica de bacias hidrográficas através de dados SRTM. Revista Brasileira de Engenharia Agrícola e Ambiental. 2010;14(8): 819-825.

28. Li A, Wang A, Liang S, Zhou W. Eco-environmental vulnerability evaluation in mountainous region using remote sensing and GIS - a case study in the upper reaches of Minjiang River, China. Ecological Modeling. 2006 Feb;192:175-187, doi:10.1016/j.ecolmodel.2005.07.005

29. Tiecher T. et al. Contribuição das fontes de sedimentos em uma bacia hidrográfica agrícola sob plantio direto. Revista Brasileira de Ciência do Solo. 2014;38(2): 639-649.

30. Nossack FA, Zimback CRL, Silva RFB, Sartori AAC. Aplicação de análise multicriterial para determinação de áreas prioritárias à recomposição florestal. Irriga. 2014;19(4):612-625, doi:10.15809/irriga.2014v19n4p612.

31. Fonsêca DN, Silva AC, Barros ACM, Silva JCB, Silva OG. Mapeamento morfodinâmico como suporte à análise de processos de degradação em áreas do município de Cabrobó-Pernambuco. Revista da Casa da Geografia de Sobral. 2017 Dez;9(2):92-107.

32. Oliveira RA, Cunha DCC, Simonetti, VC, Stroka EAB, Sabonaro DZ. Proposição de corredor ecológico entre duas Unidades de Conservação na Região Metropolitana de Sorocaba. Revista do Departamento de Geografia. 2016;32:61-71, doi:10.11606/rdg.v32i0.116467.

33. Frascareli D, Beghelli FGS, Cardoso-Silva S, Moschini-Carlos V. Heterogeneidade espacial e temporal de variáveis limnológicas no reservatório de Itupararanga associadas com o uso do solo na Bacia do Alto Sorocaba-SP. Ambiente \& Água-An Interdisciplinary Journal of Applied Science. 2015;10(4):770781.

34. Rosa AH, Silva AAMJ, Melo CA, Moschini-Carlos V, Guandique MEG, Fraceto LF, Lourenço RW. Ecologia de reservatórios e interfaces. São Paulo: Instituto de Biociências da Universidade de São Paulo. Capítulo 15, Diagnóstico ambiental e avaliação de uso e ocupação do solo visando a sustentabilidade da represa de Itupararanga, importante área da bacia do médio tietê; p. 212-231.

35. Taniwaki RH, Rosa AH, Calijuri MC, Moschini-Carlos V. Variação espacial do grau de trofia e da biomassa fitoplanctônica no reservatório de Itupararanga (São Paulo, Brasil). Holos Environment. 2011;11(2):170-179, doi:10.14295/holos.v11i2.5632.

36. Taniwaki RH, Rosa AH, Lima R, Maruyama CR, Secchin LF, Calijuri MC, Moschini-Carlos V. A influência do uso e ocupação do solo na qualidade e genotoxicidade da água no reservatório de Itupararanga, São Paulo, Brasil. Interciência. 2013 Mar;38(3):164-170.

37. Garcia MM, Barbosa FD. Análise diagnóstica da área da barragem Santa Teresa em relação à situação socioambiental e ao plano diretor de Ribeirão Preto-SP. Revista Gestão \& Sustentabilidade Ambiental. 2017 Out;6(3):52-67, doi:10.19177/rgsa.v6e3201752-67 